\title{
Residence capacity: its nature and assessment $^{\dagger}$
}

\author{
Julian C. Hughes, Marie Poole, Stephen J. Louw, Helen Greener \& Charlotte Emmett
}

\begin{abstract}
SUMMARY
This article discusses the importance of residence capacity - an individual's mental capacity to decide where they should live - and suggests how it should be assessed. People with dementia or intellectual disabilities, as well as those with other mental disorders, are sometimes required to make this decision. Assessments of capacity must be conducted with considerable care, given the implications for the individual and for their human rights. The assessment must be objective and functional: the assessor must be able specifically to demonstrate a lack of decision-making ability. Yet assessments of capacity still require evaluative decisions to be made. We suggest some basic information that should be conveyed to the person faced by the prospect of a change of residence where there is a doubt about capacity.
\end{abstract}

\section{LEARNING OBJECTIVES}

- Appreciate the importance and meaning of home for all of us, but especially when vulnerable, and therefore recognise the importance of decisions about place of residence

- Understand the legal and ethical framework that underpins the assessment of residence capacity, especially the distinction between assessments based on outcome and those based on function

- Grasp how to assess residence capacity by focusing on the requisite information

\section{DECLARATION OF INTEREST}

This work stemmed from independent research funded by the National Institute for Health Research (NIHR) under its Research for Patient Benefit programme (PB-PG-0906-11122). The views expressed in this article are those of the authors and not necessarily those of the NHS, the NIHR or the Department of Health.

'Residence capacity' can be defined as the capacity someone requires to decide where to live. Its assessment is important in a variety of mental disorders. In this article, we focus mainly on dementia, but the nature and requirements for assessment would be similar across all conditions. We also focus on the law as it pertains to England and Wales, i.e. the Mental Capacity Act 2005 (MCA), although again the nature of residence capacity and the principles for its assessment remain similar across jurisdictions.

\section{Why is residence capacity important?}

There are at least three reasons why residence capacity is important. First, we all love being at home. The place we call 'home' is usually surrounded by emotional resonances and is where we feel rooted and safe. The emotional importance of home was recognised by Mr Justice Baker in the Court of Protection when he said:

'There is, truly, no place like home, and the emotional strength and succour which an elderly person derives from being at home, surrounded by familiar reminders of past life, must not be underestimated' (CC $v$ KK and STCC [2012]: para. 70).

Going further than this, the philosopher and clinician Wim Dekkers has argued that 'being human is to dwell' (Dekkers 2011). According to the philosopher Martin Heidegger, for instance, we build 'because we dwell, that is, because we are dwellers' (Heidegger 1971). Thus, the notion of being at home is existential: it is part and parcel of what it is to be a human being in the world. So, assessing a person's capacity to make decisions about where to live has fundamental significance.

Second, if a person lacks residence capacity they are at increased risk of institutionalisation. In people with dementia admitted to a medical ward, the finding of a lack of residence capacity is likely to lead to subsequent placement in a care home (Poole 2014).

Third, residence capacity is by no means as straightforward as some other capacities. This is because the nature of home - the place where I dwell - is complex. It means different things to different people. In weighing matters up, for instance, how much weight should be given to my insistence that this is the place where I have lived with my spouse for 45 years, against your concern about my ability to cope and the risks I face? In connection with judgements about residence capacity, there is likely to be a variety of diverse and sometimes conflicting values at play (Greener 2012). The complexity surrounding these value judgements means that the assessment of residence capacity is often not straightforward and can require considerable skill.
Julian C. Hughes is a consultant in old age psychiatry in Northumbria Healthcare NHS Foundation Trust and honorary professor of philosophy of ageing at the Policy, Ethics and Life Sciences (PEALS) Research Centre, Newcastle University. His research focuses on ethics and philosophy in connection with ageing and dementia. He is deputy chair of the Nuffield Council on Bioethics. Marie Poole is a health services researcher and doctoral student at the Institute of Health and Society, Newcastle University. Her research interests are experiences of dementia, focusing on improving healthcare and services. Stephen J. Louw is a consultant physician in the Newcastle upon Tyne Hospitals NHS Foundation Trust. He co-founded the Trust's Clinical Ethics Advisory Group and is lead of the Trust's Mental Capacity Act and Deprivation of Liberty Group. Helen Greener is consultant psychiatrist in gender dysphoria and the clinical lead at the Northern Region Gender Dysphoria Service, Northumberland, Tyne and Wear NHS Foundation Trust. She has an interest in the Mental Capacity Act and how it relates to the practice of all medical professionals. Charlotte Emmett is a senior law lecturer in the School of Law, Northumbria University. Her research focuses on mental health law, particularly capacity and consent issues relating to older people with mental disorder. Correspondence Professor Julian C. Hughes, Ash Court, North Tyneside General Hospital, Rake Lane, North Shields, Tyne and Wear NE29 8NH, UK. Email: julian. hughes@ncl.ac.uk

${ }^{\dagger}$ For a related commentary see $\mathrm{pp}$. 313-314, this issue. 


\section{Context}

Whereas some types of capacity, such as testamentary capacity, involve specific tests (Jacoby 2013), and tools have been developed to assess them (Vellinga 2004), residence capacity has been relatively ignored in the literature, despite its importance (for a review see Greener 2012).

Ripley et al (2008) developed an algorithm to assess capacity to enter a care home that conforms with the principles outlined in the MCA, but we need to turn to the Act itself, in combination with its principles, for best guidance. In England and Wales, the MCA established in statute law a single test for incapacity: 'a person lacks capacity in relation to a matter if at the material time he is unable to make a decision for himself in relation to the matter because of an impairment of, or a disturbance in, the functioning of, the mind or brain' (MCA: section 2). The person will be unable to make the required decision if, owing to the impairment or disturbance, he or she is unable to understand, retain, use or weigh the relevant information or to communicate the decision (MCA: section 3). Principles in section 1 of the Act (Box 1) establish the legal context for judgements about residence capacity in England and Wales.

To return to the difficulties that stem from the need for evaluative decisions, it can be seen that my insistence on remaining in my spousal home, despite the risks that the professionals have highlighted, might be regarded as a failure to weigh things up adequately owing to my mental disorder (in which case I lack capacity), but might alternatively be regarded as simply an unwise decision. In the context of the MCA, therefore, we are immediately struck by the importance of values-based judgements (Fulford 2012). But there is also relevant case law.

\section{The case of JB: consent to treatment}

In Heart of England NHS Foundation Trust $v J B$ [2014], Mr Justice Jackson considered the case of a 62-year-old woman identified as JB. The

B0X 1 The MCA principles regarding capacity

'A person must be assumed to have capacity unless it is established that he lacks capacity.

A person is not to be treated as unable to make a decision unless all practicable steps to help him to do so have been taken without success

A person is not to be treated as unable to make a decision merely because he makes an unwise decision.

(Mental Capacity Act 2005: section 1) decision concerned amputation of her lower leg because of gangrene. Her putative lack of capacity was said to stem from her diagnosis of chronic paranoid schizophrenia. Although the capacity under consideration was the capacity to consent to treatment, Justice Jackson made a number of comments pertinent to assessment of residence capacity. For instance:

'The temptation to base a judgement of a person's capacity upon whether they seem to have made a good or bad decision, and in particular upon whether they have accepted or rejected medical advice, is absolutely to be avoided. That would be to put the cart before the horse or [...] to allow the tail of welfare to wag the dog of capacity. Any tendency in this direction risks infringing the rights of that group of persons who, though vulnerable, are capable of making their own decisions. Many who suffer from mental illness are well able to make decisions about their medical treatment, and it is important not to make unjustified assumptions to the contrary' (para. 7).

Later in his judgment, Justice Jackson made the following point, which is also relevant to residence capacity:

'What is required here is a broad, general understanding of the kind that is expected from the population at large. JB is not required to understand every last piece of information about her situation and her options: even her doctors would not make that claim. It must also be remembered that common strategies for dealing with unpalatable dilemmas - for example indecision, avoidance or vacillation - are not to be confused with incapacity. We should not ask more of people whose capacity is questioned than of those whose capacity is undoubted' (para. 26).

So, too, decisions about change of residence in connection with dementia often invite avoidance and vacillation because the thought of moving into care is unpalatable. The judge said of JB:

'Her tendency at times to be uncommunicative or avoidant and to minimise the risks of inaction are understandable human ways of dealing with her predicament and do not amount to incapacity' (para. 39).

Again, people with dementia or an intellectual disability (learning disability) might well, on account of their mental difficulties, be less than communicative and might minimise risks. However, these traits do not in themselves prove that they lack the requisite capacity, and the burden of proof lies with those who wish to say that they do; otherwise, capacity must be assumed (Box 1). The case of JB, therefore, offers pertinent guidance in relation to residence capacity assessments.

\section{The House of Lords and the Supreme Court}

Residence capacity is important because of its implications for human rights. A Select 
Committee of the House of Lords reported on the Mental Capacity Act in 2014. While celebrating the innovative nature of the Act and noting its potential 'to transform the lives of many' (House of Lords 2014: p. 6), the Committee went on to say that the implementation of the Act had not met expectations. In particular, 'the prevailing cultures of paternalism (in health) and riskaversion (in social care) have prevented the Act from becoming widely known or embedded' (House of Lords 2014: p. 6).

The Select Committee's report was published on 13 March 2014, and on 19 March 2014 the Supreme Court handed down its judgment on $P$ (by his litigation friend the Official Solicitor) $v$ Cheshire West and Chester Council \& Anor [2014]. This concerned the criteria for judging whether or not the living arrangements made for a person who lacked capacity amounted to a deprivation of liberty. The judgment has had significant repercussions, mainly because it establishes, in para. 49, an 'acid test' for deprivation of liberty, namely that the person is under continuous supervision and control and is not free to leave. The stringency of this test means that many people with dementia who lack residence capacity and are moved into residential care may well thereby be deprived of their liberty. The same holds true of people with an intellectual disability who live in a variety of institutional settings. Hence, as with any type of capacity, residence capacity is important because human rights are at stake; and, as the Supreme Court's judgment shows, there is a real chance that the right to liberty will be compromised as a consequence of an assessment of residence capacity.

\section{Case vignettes $^{a}$}

\section{Mr Jones in hospital}

Mr Jones, who is 82 years old, was found on the floor of his kitchen by a neighbour. In hospital, a urinary tract infection was diagnosed. But his neighbour, and subsequently his daughter, confirmed that he had had memory problems for some while. He remained confused, even when the infection was treated. An occupational therapy assessment in the ward kitchen showed that he was unsafe making a pot of tea. He had lived alone since the death of his wife and his house is now described as chaotic and squalid. Questions are raised about whether or not Mr Jones should be allowed to return home. He says he wishes to go home, but he thinks he does his own shopping, whereas his neighbour does this for him. His daughter feels he would be safer in a care home.

\section{Mrs Jarvis at home}

Mrs Jarvis is 79 years old and, since her husband died 4 years ago, has lived alone in their marital home of over 50 years. She has moderately severe vascular dementia and has had a number of falls, for which she has a telecare alarm service to summon help. She continues to fall and will sometimes activate the alarm, but sometimes does not. At other times she rings the alarm service just because she is lonely. She sometimes wanders out of her house. This has been happening more often, including at night, and sometimes involves the police. Her family are very worried about her. Home care visit three times a day to make sure she is washed and to provide food. But she will not always eat the food, which is later found discarded in various places in the house. Occasionally, she does not, despite being prompted, accept her medication. Family and professionals are putting pressure on Mrs Jarvis to accept a move into a residential care home. But she steadfastly refuses to consider this option.

The cases of Mr Jones and Mrs Jarvis are not unique. From the information presented it is not possible to say with any certainty whether or not they have residence capacity. Careful assessments will be required to determine whether they do or not.

Where assessments of residence capacity have to be made on acute medical or surgical wards, as for Mr Jones, issues around time and timing become important (Poole 2014). Assessing the person's residence capacity in the context of delirium is usually a waste of time: the assessment needs to be undertaken when the person's cognitive function is as optimal as it is likely to be. This poses a significant problem for acute units, with pressure on beds, that cannot always afford to wait. Step-down or rehabilitation units provide a better setting for such assessments, but they are not always available. In addition, the assessment of residence capacity inevitably takes time (Box 2).

A lot of information (see below) is required before the assessment can even be undertaken. It must be carried out in circumstances that are optimal for the person. They must be able to hear and see adequately; if special means of communication are a. Mr Jones and Mrs Jarvis are fictitious characters. required, these should be available; and so on. In

\section{BOX 2 Delirium, time and the UN Convention on the Rights of Persons with Disabilities}

In acute medical settings, delirium often presents with underlying dementia. In such cases, it is impossible to be certain what the person's level of cognitive functioning will be once the delirium is treated. In addition, not all deliriums resolve quickly. In this situation, time becomes a key issue. Not only do assessments take time, they also need to be carried out at the appropriate time (Poole 2014). Providing a setting in which this can occur is a challenge. But the United Nations Convention on the Rights of Persons with Disabilities makes it plain, in Article 12(2), that States 'shall recognize that persons with disabilities enjoy legal capacity on an equal basis with others in all aspects of life'. And then, in Article 12(3), the Convention stipulates that States must provide the support these individuals require to exercise their legal capacity. Countries which have signed the Convention (such as the UK) are thereby bound to support this sort of decision-making, despite the time and other resources required. 
keeping with the principles of the MCA (Box 1), 'all practicable steps' must be taken to help the person make a decision.

\section{Approaches to assessment: outcome $v$. functional}

There are three approaches to the assessment of capacity (Box 3), based on the person's status, the likely outcome or their functional ability. Professionals are mostly aware that assessments based on status should be avoided because they are unfairly discriminatory: a person should not be assumed to lack capacity just because they have dementia or an intellectual disability.

However, clinicians and others tend to conflate the outcome and functional approaches (Emmett 2013). The MCA requires that a functional approach be pursued. Despite this, people who have to make decisions for others tend to be protective of them and this tendency influences judgements about capacity. In $C C{ }_{V} K K$ and $S T C C$ [2012], Mr Justice Baker made just this point in para. 25 of his ruling:

'in cases of vulnerable adults, there is a risk that all professionals involved with treating and helping that person - including, of course, a judge in the Court of Protection - may feel drawn towards an outcome that is more protective of the adult and thus, in certain circumstances, fail to carry out an assessment of capacity that is detached and objective. On the other hand, the court must be equally careful not to be influenced by sympathy for a person's wholly understandable wish to return home'

The case concerned an 82-year-old woman, KK, who had hemiplegia, Parkinson's disease and vascular dementia. She was totally dependent on others for her personal care, frequently sought help by the use of a telecare alarm service and showed considerable anxiety. Finally, she was admitted to a nursing home with dehydration and a urinary

B0X 3 Approaches to capacity assessment

Status Capacity is determined by the person's status as, for example, someone who is old, has an intellectual disability or dementia, has speech problems, has had a stroke

Outcome Capacity is determined by what is likely to be a good outcome for the person, as judged by others and by the person's tendency to pursue that good outcome

Functional Capacity is determined by a test of the person's functional ability (as judged under the Mental Capacity Act by their ability to understand, retain, weigh and communicate) to make a decision on the basis of the information available tract infection. But she wanted to return home. Her case involved a number of professionals assessing her capacity on a number of occasions. They all found that she lacked residence capacity, but $\mathrm{Mr}$ Justice Baker determined otherwise. In para. 65, he reiterated the point about the importance of the objective test of capacity being made without reference to what might be best for the person and emphasised again the saliency of home:

'There is, I perceive, a danger that professionals, including judges, may objectively conflate a capacity assessment with a best interests analysis and conclude that the person under review should attach greater weight to the physical security and comfort of a residential home and less importance to the emotional security and comfort that the person derives from being in their own home'.

The issues that weigh on the minds of professionals are often those of safety and risk, but Mr Justice Baker was keen to cite (in para. 66) a lecture delivered by Lord Justice Munby, in which he made this powerful statement:

'The State must be careful to ensure that in rescuing a vulnerable adult from one type of abuse it does not expose her to the risk of treatment at the hands of the State which, however well intentioned, can itself end up being abusive of her dignity, her happiness and indeed of her human rights. What good is it making someone safer if it merely makes them miserable? None at all! And if this is where safeguarding takes us, then is it not, in truth, another form of abuse - and, moreover, abuse at the hands of the State?'

Unusually in cases where capacity is in doubt, KK actually appeared in court to give evidence and when pressed about the possibility that she might fall ill, she made the arresting assertion: 'If I die on the floor, I die on the floor. I'd rather die in my own bungalow, I really would' (para. 50). The judge felt that this demonstrated her ability to weigh things up. As he opined,

'I venture to think that many and probably most people in her position would take a similar view. It is not an unreasonable view to hold. It does not show that [sic] a lack of capacity to weigh up information. Rather it is an example of how different individuals may give different weight to different factors' (para. 73).

This is a helpful demonstration of how legal minds consider these matters, but it also reveals a tension. On the one hand, there is the requirement to test capacity in an objective and functional manner; on the other hand, it shows that evaluative judgements are still required. We should, however, recall the advice of Mr Justice Jackson in the JB case: 'We should not ask more of people whose capacity is questioned than of those whose capacity is undoubted'. Tests of capacity are tests, but they should not be unreasonable tests. And there is 
evidence that there are strategies that can improve the likelihood of a person being found to have capacity, for instance by attending to the physical environment: it should be quiet and private. 'A well-conducted capacity assessment can [...] become a therapeutic intervention' (Hotopf 2013).

\section{The 'information'}

In order to have capacity, the person must be assessed as able to understand, retain and weigh the relevant information before communicating a decision. But what information? It seems important to try to pin down the key elements that need to be tested when a question about residence capacity has been raised.

Manuela Sykes was an 89-year-old woman with dementia whose case was heard in the Court of Protection (Westminster City Council v Manuela Sykes [2014]). The judgment mainly concerned a detailed assessment of Manuela Sykes's best interests. Her lack of capacity was not at issue. But District Judge Eldergill usefully set out the grounds for reaching this conclusion. He said:

\begin{abstract}
'she cannot recall the circumstances and behaviour that caused others to remove her from her own home to hospital and to transfer her to residential care. Lacking this information, she does not accept that she had significant problems at home, nor therefore that she requires a significant package of care and support. Nor can she appreciate that, without additional care, it is likely that the problems will be the same as before, because the situation is the same as before' (para. 7).
\end{abstract}

In Box 4 we have set out some potential items of information that might form the basis of the test of residence capacity. We have proposed similar items elsewhere (Emmett 2013), but here

\section{BOX 4 Information necessary for residence capacity}

- The person should know why a change of residence is being proposed: what have the problems been that have caused a concern (e.g. they should know why they had to come into hospital or what has caused a worry in the community)

- The person should know what is being proposed (e.g. they should know that it is being suggested they should move into a care home)

- The person should be informed if there are other options (e.g. that they could go home but extra help is recommended because of the risks identified)

- The person should understand the likely consequences of making any particular decision, including a decision not to follow the advice being given, as well as the consequences of making no decision at all they are developed and generalised to fit different circumstances. Of course, residence capacity will only be an issue when it is felt that a change of residence might be beneficial. So the information required to be known will be specific, even if there are various options open to the person. A good example of the level of detail required is provided in the judgment of Mrs Justice Theis in a long-running case concerning, among other things, residence capacity for a 29-year-old man (L) with an intellectual disability $(L B X \vee K, L$ and $M$ [2013]). Some of the relevant considerations for residence capacity included there being two options open to L, what they were, the sort of facilities the places had, the sort of area they were in, specific known risks, what activities $\mathrm{L}$ would be able to do if he lived in each place, and so on. But L had to understand these things only 'in broad terms'.

Thus, returning to our case vignettes, the information to be put to Mr Jones might be:

1 that there are concerns that he had a fall because he was unwell and worries that his memory problems might mean that he is not able to cope at home on his own; so

2 it is being suggested that he should go into a care home; but

3 an alternative would be for him to go home with professional carers coming in to see him several times a day; and

4 he should understand that if he goes into a care home it might well become the place he lives permanently and, alternatively, if he goes home and accepts the care package it cannot be guaranteed that he will not run into similar problems again in the future.

Mrs Jarvis, meanwhile, must understand that:

1 there is a lot of concern about her safety at home because of the problems being caused by her dementia; so

2 it is being suggested that she should live in a care home; alternatively,

3 attempts could be made to enhance the care she receives at home; but

4 if she stays at own home, and especially if she does not accept care, she will be putting herself at risk in a variety of ways that would be lessened in a care home, albeit she would lose her independence and might still have falls.

This information would need to be presented to Mr Jones and to Mrs Jarvis under the appropriate circumstances, with enough time in a quiet and comfortable environment. They are allowed to make unwise decisions (Box 1), but then the assessor must be able to indicate why the decision seemed unwise rather than incapacitous; and we
MCQ answers

$\begin{array}{lllll}1 \mathrm{c} & 2 \mathrm{e} & 3 \mathrm{~b} & 4 \mathrm{a} & 5 \mathrm{c}\end{array}$ 
should recall Mr Justice Jackson stating in the case of JB: 'We should not ask more of people whose capacity is questioned than of those whose capacity is undoubted'. When this information has been presented to Mr Jones and Mrs Jarvis, the decision maker must determine whether or not they can understand, retain and weigh it up before communicating their decisions (Hotopf 2013). If, on balance, they can do this, they have residence capacity; if they cannot, they lack this capacity because the presumption of capacity has been rebutted.

\section{Conclusions}

Residence capacity is an important decisionmaking capacity that commonly needs to be assessed and should be assessed with considerable care, given its implications for the person and for human rights. It will often involve evaluative decisions, but it should be based on a functional assessment of the person's capacity. We have suggested some basic information that should be conveyed to the person faced by the prospect of a change of residence where there is a doubt about capacity. If the person lacks capacity, then a decision will have to be made in the person's best interests, which must also be assessed fairly and fully (Hughes 2013).

\section{References}

Dekkers W (2011) Dwelling, house and home: towards a home-led perspective on dementia care. Medicine, Health Care and Philosophy, 14: $291-300$

Emmett C, Poole M, Bond J, et al (2013) Homeward bound or bound for a home? Assessing the capacity of dementia patients to make decisions about hospital discharge: comparing practice with legal standards. International Journal of Law and Psychiatry, 36: 73-82.

Fulford KWM, Peile E, Carroll H (2012) Essential Values-Based Practice: Clinical Stories Linking Science with People. Cambridge University Press.

Greener H, Poole M, Emmett C, et al (2012) Value judgements and conceptual tensions: decision-making in relation to hospital discharge for people with dementia. Clinical Ethics, 7: 166-74.

Heidegger M (1971) Building dwelling thinking. In Poetry, Language, Thought (ed M Heidegger, trans A Hofstadter): 145-61. Harper \& Row.

Hotopf M (2013) The assessment of mental capacity. In Mental Capacity Legislation: Principles and Practice (eds R Jacob, M Gunn, A Holland): 15-32. RCPsych Publications.

House of Lords Select Committee on the Mental Capacity Act 2005 (2014) Mental Capacity Act 2005: Post-Legislative Scrutiny. TSO (The Stationery Office).

Hughes JC (2013) Best interests. In Mental Capacity Legislation: Principles and Practice (eds R Jacob, M Gunn, A Holland): 33-53. RCPsych Publications.

Jacoby R (2013) Testamentary capacity. In Oxford Textbook of Old Age Psychiatry (2nd edn) (eds T Dening, A Thomas): 797-804. Oxford University Press.

Poole M, Bond J, Emmett C, et al (2014) Going home? An ethnographic study of assessment of capacity and best interests in people with dementia being discharged from hospital. BMC Geriatrics, 14: 56 .

Ripley S, Jones S, Macdonald A (2008) Capacity assessments on medical in-patients referred to social workers for care home placement. Psychiatric Bulletin, 32: 56-9.

Vellinga A, Smit JH, van Leeuwen E, et al (2004) Instruments to assess decision-making capacity: an overview. International Psychogeriatrics, 16: $397-419$

\section{Cases}

CC v KK and STCC [2012] EWHC 2136 (COP).

Heart of England NHS Foundation Trust $v$ JB [2014] EWCOP 342.

LBX $\vee$ K, L and M[2013] EWHC 3230 (Fam), [2013] MHLO 148.

$P$ (by his litigation friend the Official Solicitor) $v$ Cheshire West and Chester Council \& Anor [2014] UKSC 19.

Westminster City Council v Manuela Sykes [2014] EWHC B9 (COP), [2014] EWCOP B9.

\section{MCQs}

Select the single best option for each question stem

1 The notion of 'home':

a is lost in dementia

b depends mostly on the cognitive ability to recall an exact address

c links with our existential concerns as dwellers in the world

$\mathrm{d}$ is not relevant to residence capacity

$\mathrm{e}$ is ignored in legal judgments about place of residence.

2 Residence capacity:

a is assessed using the same specific test in all circumstances

b does not need to be assessed if the person is to be deprived of their liberty

c is never an issue for people with mild intellectual disabilities

$\mathrm{d}$ is considered to be lacking, in England and Wales, if the person makes an unwise decision e involves an understanding of any alternatives when it comes to deciding where to live.

3 In assessing residence capacity:

a the process must start as soon as the person is admitted to hospital

b the person needs to understand the information offered only in broad terms

c it is best to assume the person lacks capacity so that they can demonstrate that this is not the case

d knowing who else the person will be living with will always be irrelevant to whether they have capacity

e indecision is a sure sign of incapacity.

4 A functional approach to capacity:

a forms the basis of statute law on the matter in England and Wales

b requires the use of the Mini-Mental State Examination or similar screening tool for cognitive assessment c allows the assessor to make a judgement about what is best for the person as part of the assessment

$d$ is unnecessary in the face of a definitive diagnosis of intellectual disability or dementia

e should be undertaken as swiftly as possible in order not to upset the person.

5 'Information' relevant to residence capacity will always include:

a knowledge of the architectural history of the proposed place of residence

b the exact address, including postcode, of the proposed place of residence

c broad details about the proposed place of residence

$d$ the names of the staff in the proposed place of residence

e clear details about the single option facing the person. 